\title{
Three-Dimensional Numerical Analysis of the Tunnel for Polyaxial State of Stress
}

\author{
Wenge Qiu, Chao Kong, and Kai Liu \\ Key Laboratory of Transportation Tunnel Engineering, Ministry of Education, School of Civil Engineering, \\ Southwest Jiaotong University, Chengdu 610031, China
}

Correspondence should be addressed to Chao Kong; 394757022@qq.com

Received 10 May 2015; Accepted 8 June 2015

Academic Editor: Jurgita Antucheviciene

Copyright (C) 2015 Wenge Qiu et al. This is an open access article distributed under the Creative Commons Attribution License, which permits unrestricted use, distribution, and reproduction in any medium, provided the original work is properly cited.

\begin{abstract}
The aim of this study is to have a comprehensive understanding of the mechanical behavior of rock masses around excavation under different value of intermediate principal stress. Numerical simulation was performed to investigate the influence of intermediate principal stress using a new polyaxial strength criterion which takes polyaxial state of stress into account. In order to equivalently substitute polyaxial failure criterion with Mohr-Coulomb failure criterion, a mathematical relationship was established between these two failure criteria. The influence of intermediate principal stress had been analyzed when Mohr-Coulomb strength criterion and polyaxial strength criterion were applied in the numerical simulation, respectively. Results indicate that intermediate principal stress has great influence on the mechanical behavior of rock masses; rock strength enhanced by intermediate principal stress is significant based on polyaxial strength criterion; the results of numerical simulation under Mohr-Coulomb failure criterion show that it does not exert a significant influence on rock strength. Results also indicate that when intermediate principal stress is relatively small, polyaxial strength criterion is not applicable.
\end{abstract}

\section{Introduction}

With respect to underground engineering, rock strength is one of the most important factors that affect stability of underground structure. Among the factors that affect rock strength, cohesion, internal friction angle, fissures, joints, and stress state of rock mass have a significant influence on rock strength [1].

When the ratio of the spacing of discontinuities is far smaller than the excavation dimension, the effect that discontinuities exert on excavation is also relatively small. Moreover, this effect brought by discontinuities is deemed to be acting on the whole rock mass and the whole underground structure rather than on partial rock mass and partial supporting structure system. As a result, discontinuity rock mass can be thought of as continuum. At the same time, MohrCoulomb failure criterion is presented that only cohesion and internal friction angle are considered to describe strength of rock mass. With the rapid development of numerical simulation brought by superior performance of computer, Mohr-Coulomb failure criterion is widely applied as a simple and practical form in numerical simulation of geotechnical field.

Under Mohr-Coulomb failure criterion, major principal stress $\sigma_{1}$ can be predicted if minor principal stress $\sigma_{3}$ is determined. Major principal stress $\sigma_{1}$ is written as

$$
\sigma_{1}=f\left(\sigma_{3}, k\right) \text {, }
$$

where $k$ are "material constants" that could depend, among other factors, on rock type and quality, weathering, loading history, or strain [2]. In Mohr-Coulomb failure criterion, both major principal stress $\sigma_{1}$ and minor principal stress $\sigma_{3}$ are considered. Note that Mohr-Coulomb failure criterion does not take into account intermediate principal stress $\sigma_{2}$. According to Wang and Kemeny [3], however, intermediate principal stress $\sigma_{2}$ has a significant influence on $\sigma_{1}$ even if $\sigma_{3}$ equals zero. Senent et al. [2] thought that although enhancement of rock strength by intermediate principal stress $\sigma_{2}$ was seriously affected by the defeats in the rock mass, rock mass could also be modeled as homogeneous media with reduced strength property. 
In general, under both deep-buried and squeezing geoenvironment, rock mass is always in polyaxial stress state, shown in Figure 1, where longitudinal stress was intermediate principal stress $\left(\sigma_{2}\right)$. Excavation will bring about stress redistribution in rock mass. $\sigma_{3} / \sigma_{1}$ is called lateral pressure coefficient $K$; it can influence the failure mode of tunnel during excavation [4]. When $K$ is smaller, the initial damage appears in arch foot and arch; when $K$ is bigger, the initial damage appears in sidewall and arch; tensile damage is the main failure mode. But intermediate principal stress $\sigma_{2}$ is not relaxed significantly with advance of excavation $[5,6]$. Polyaxial strength criterion has been introduced by Singh et al. [5]. They initiated a large number of studies on the polyaxial constitutive models to prove the applicability of underground engineering in severe squeezing conditions, explaining the differences between what was predicted by traditional elastoplasticity theory and that by observations. Back analysis of the data obtained from field reveals that rock masses around the excavation have a strength enhancement owing to the effect of intermediate principle stress $\sigma_{2}$. Singh et al. [5] proposed a semiempirical approach that incorporates the effect of intermediate principal stress $\sigma_{2}$ in the conventional formula of Mohr-Coulomb failure criterion by substituting $\sigma_{3}$ with the average value of $\sigma_{2}$ and $\sigma_{3}$ at the second term:

$$
\begin{gathered}
\text { Mohr-Coulomb: } \sigma_{1}-\sigma_{3}=\sigma_{\mathrm{cr}}+\sigma_{3} A \text {, } \\
\text { polyaxial criterion: } \sigma_{1}-\sigma_{3}=\sigma_{\mathrm{cr}}+\frac{\sigma_{3}+\sigma_{2}}{2} A \text {, }
\end{gathered}
$$

where $A=2 \sin \varphi /(1-\sin \varphi)$.

Yield curves of the two failure criteria on $\pi$-plane are shown in Figure 2.

Polyaxial failure criterion has gradually been accepted by scholars and engineers. Scussel and Chandra [7] verified the precision and validity of this failure criterion through actual project [8]. Scussel and Chandra [9] used Fish computer language of $\mathrm{Flac}^{3 \mathrm{D}}[10]$ to establish the constitutive model of polyaxial failure criterion with satisfactory results. However, due to limitations of Fish computer language itself, this failure criterion is not widely applied into the commercial software. When polyaxial failure criterion is applied into commercial software, relatively poor efficiency of calculation is another factor that may explain its unpopularity.

This paper begins with the effect of intermediate principal stress $\sigma_{2}$ on the behavior of rock masses using MohrCoulomb failure criterion in $\mathrm{Flac}^{3 \mathrm{D}}$. Then, according to the established mathematic relationship between MohrCoulomb failure criterion and polyaxial failure criterion, polyaxial failure criterion is equivalently substituted with Mohr-Coulomb failure criterion. As a result, polyaxial failure criterion is introduced in Flac ${ }^{3 \mathrm{D}}$. Meanwhile numerical simulation is conducted using polyaxial failure criterion to investigate the effect of intermediate principal stress $\sigma_{2}$ on the behavior of rock masses. In the end, comparisons of numerical results between these two failure criteria are made and applicability of these two failure criteria is discussed.
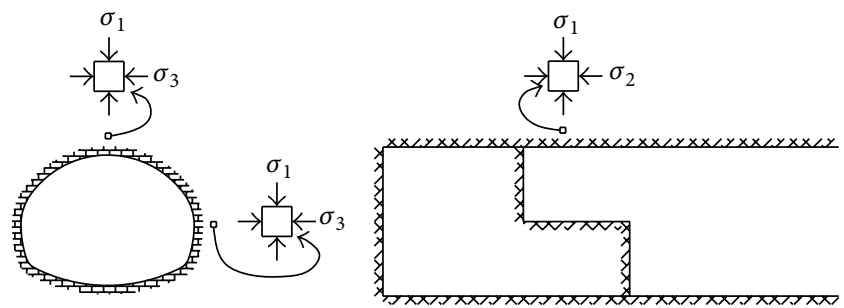

FIGURE 1: Stress state of rock mass during tunneling.

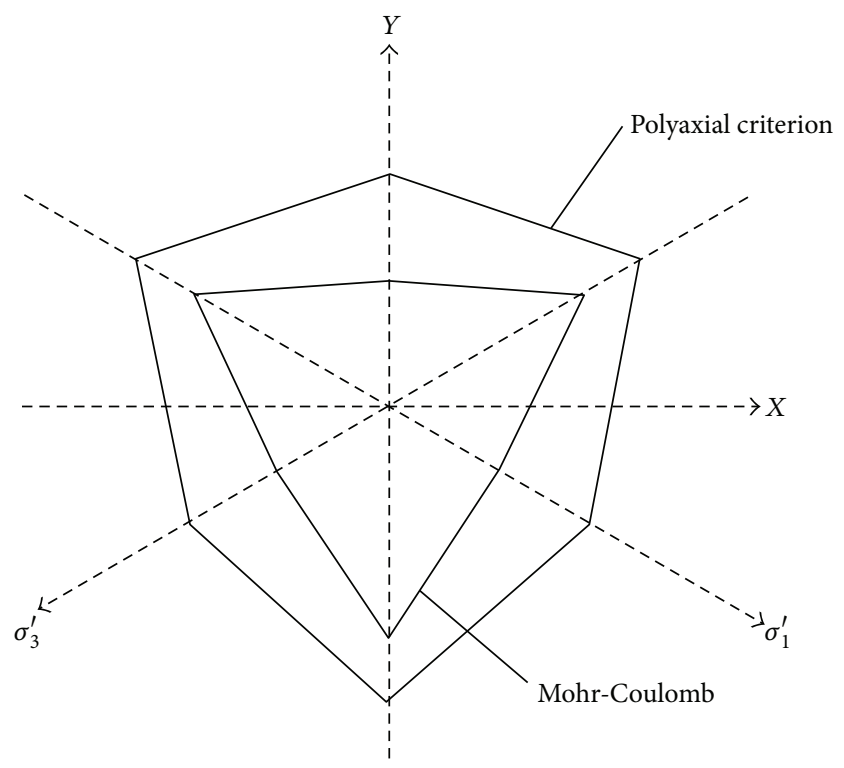

FIGURE 2: Yield curves on $\pi$-plane.

TABLE 1: Property of rock mass.

\begin{tabular}{lcccc}
\hline$\phi$ & $c$ & $P_{v}$ & $P_{h}$ & $P_{0}$ \\
30 & $0.2 \mathrm{MPa}$ & $15 \mathrm{MPa}$ & $15 \mathrm{MPa}$ & $15 \mathrm{MPa}$ \\
\hline UCS & $E$ & $\nu$ & $\lambda$ & $r_{i}$ \\
$1.89 \mathrm{MPa}$ & $3 \mathrm{Gpa}$ & 0.3 & 1 & $3.2 \mathrm{~m}$ \\
\hline
\end{tabular}

\section{Analysis of $\sigma_{2}$ Using MOHR-Coulomb Failure Criterion}

2.1. Description of Numerical Model. The typical example of deep-buried circular tunnel subjected to a hydrostatic in situ stress field shown in Figure 3 has been selected. Property of geomaterials is shown in Table 1 [11].

Numerical simulation is performed using MohrCoulomb failure criterion of Flac ${ }^{3 \mathrm{D}}$ [10]. The $X$-axis and $Y$-axis are in the cross section perpendicular to the tunnel longitudinal direction ( $Z$-axis). The model size is $60 \mathrm{~m} \times$ $60 \mathrm{~m} \times 40 \mathrm{~m}(X \times Y \times Z)$. As shown in Figure 3, the normal (vertical) displacement is fixed at the model base. For the lateral boundary condition, stress boundary is applied. In order to simulate the effect of intermediate principal stress well and eliminate other factors affecting the results, numerical simulation adopts $3 \mathrm{D}$ model with full excavation 


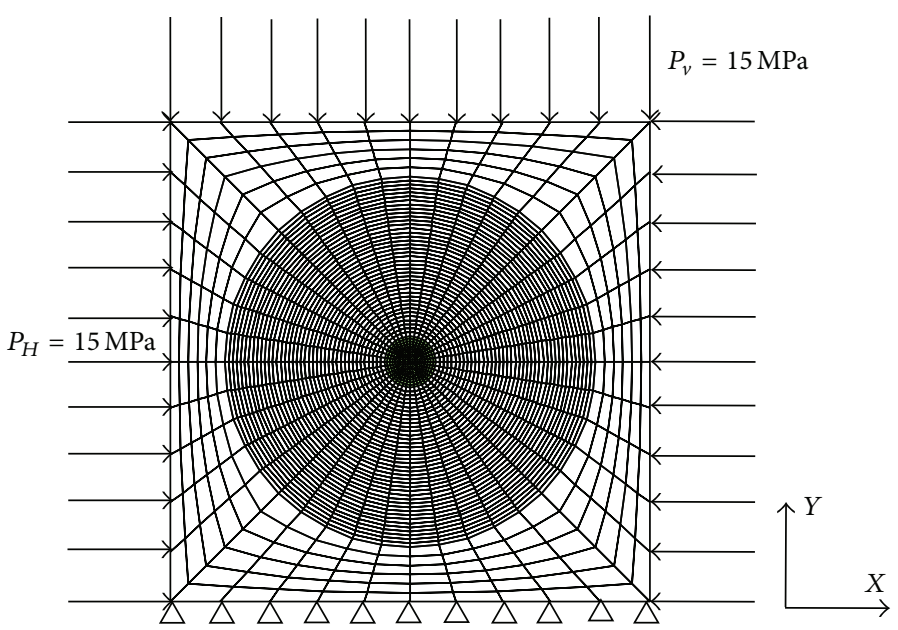

(a) Front view

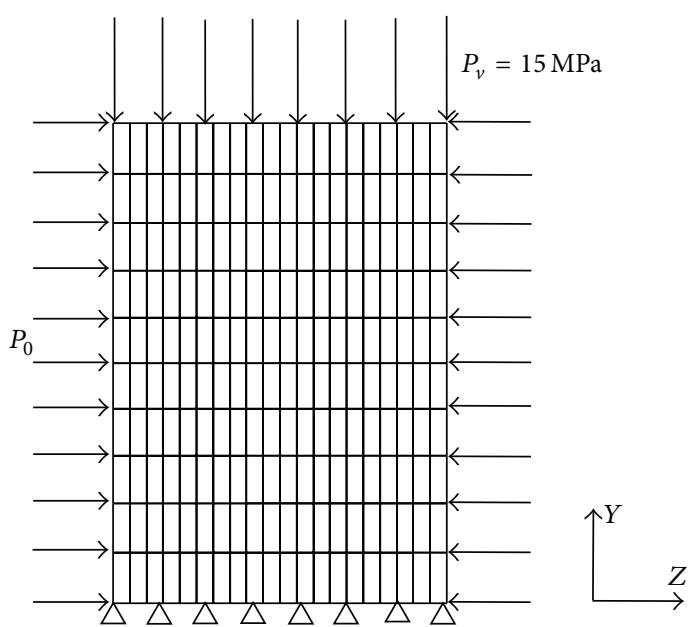

(b) Lateral view

FIGURE 3: Numerical simulation.

method. During the process of simulation, blasting cycle is $1 \mathrm{~m}$ and support system is not installed.

The research includes two cases. Case I: intermediate principle stress $\sigma_{2}=15 \mathrm{MPa}$; case II: intermediate principle stress $\sigma_{2}=10 \mathrm{MPa}$.

2.2. Numerical Results. In order to minimize boundary effect, the central plane (perpendicular to tunnel longitudinal direction, $z=-20 \mathrm{~m}$ ) of the model is selected as the analysis plane. As displacement and size of plastic zone as well as stress distribution can well reflect the effect on the mechanical behavior of rock masses, this research analyzes the results mainly from three aspects mentioned above. In the two cases above, displacement, size of plastic zone, and stress distribution are shown, respectively, in Figures 4 6.

As shown in Figures 4 and 5, value of crown displacement in Figure 4(a) is approximate to that in Figure 4(b); radius of plastic zone in Figure 5(a) is close to that in Figure 5(b). Specifically, the result indicates that when $\sigma_{2}=10 \mathrm{MPa}$, displacement of crown and radius of plastic zone are $26.97 \mathrm{~cm}$ and $12.64 \mathrm{~m}$, respectively. When $\sigma_{2}=15 \mathrm{MPa}$, displacement of crown and radius of plastic zone are $27.75 \mathrm{~cm}$ and $12.64 \mathrm{~m}$, respectively. As shown in Figure 6, when intermediate principal stresses are $10 \mathrm{MPa}$ and $15 \mathrm{Mpa}$, respectively, the distribution of tangential stress shares the same characteristics and distribution of radial stress also shares the same characteristics. As a result, effect of intermediate principal stress $\sigma_{2}$ on rock strength enhancement is not well reflected by deformation and stress and by area of plastic zone when MohrCoulomb failure criterion is applied in the numerical simulation. For squeezing geocondition (when sigma-2 is much bigger), applying Mohr-Coulomb failure criterion to simulate rock strength enhancement brought by $\sigma_{2}$ cannot be realized.

\section{Analysis of $\sigma_{2}$ Using Polyaxial Failure Criterion}

3.1. Establishment of Mathematic Relationship between MohrCoulomb and Polyaxial Criterion. A mathematic relationship between Mohr-Coulomb failure criterion and polyaxial failure criterion is established. This relationship is well reflected by the equivalent mechanical parameters inputted into MohrCoulomb failure criterion in Flac ${ }^{3 \mathrm{D}}$ to equivalently substitute polyaxial failure criterion [11] (equivalent Mohr-Coulomb failure criterion). The established mathematic relationship is written as

$$
\begin{array}{r}
\text { polyaxial: } \sigma_{1}=N_{\phi}^{\prime} \sigma_{3}+\sigma_{\mathrm{cr}}^{\prime}, \\
\text { Mohr-Coulomb: } \sigma_{1}=N_{\phi} \sigma_{3}+\sigma_{\mathrm{cr}},
\end{array}
$$

where $N_{\phi}=(1+\sin \varphi) /(1-\sin \varphi), N_{\phi}^{\prime}=1 /(1-\sin \varphi), \sigma_{\mathrm{cr}}=$ $2 c \cos \varphi /(1-\sin \varphi), \sigma_{\mathrm{cr}}^{\prime}=\left(\mathrm{UCS}+\sigma_{2}(A / 2)\right), A=2 \sin \varphi /(1-$ $\sin \varphi)$.

Equivalent Mohr-Coulomb failure criterion is expressed as follows:

$$
\text { Equivalent Mohr: } \sigma_{1}=N_{\phi(\mathrm{eq})}^{\prime} \sigma_{3}+\sigma_{\mathrm{cr}(\mathrm{eq})}^{\prime},
$$

where $N_{\varphi(\text { eq })}^{\prime}=\left(1+\sin \varphi^{\prime}\right) /\left(1-\sin \varphi^{\prime}\right)$ and $\sigma_{\mathrm{cr}(\mathrm{eq})}^{\prime}=2 c \cos \varphi^{\prime} /$ $\left(1-\sin \varphi^{\prime}\right)$.

If (3) is equal to (5), (6) and (7) have to be met:

$$
\begin{aligned}
& N_{\phi}^{\prime}=N_{\phi(\mathrm{eq})}^{\prime}, \\
& \sigma_{\mathrm{cr}}^{\prime}=\sigma_{\mathrm{cr}(\mathrm{eq})}^{\prime} .
\end{aligned}
$$

Equivalent internal friction angle is expressed as

$$
\varphi^{\prime}=2 \tan ^{-1} \frac{\sin \varphi /(2-\sin \varphi)}{1+\sqrt{1+(\sin \varphi /(2-\sin \varphi))^{2}}} .
$$

Equivalent cohesion is expressed as

$$
c^{\prime}=\left(\mathrm{UCS}+\sigma_{2} \frac{A}{2}\right) B
$$

where $A=2 \sin \varphi /(1-\sin \varphi)$ and $B=(1-\sin \varphi) /(2-$ $\sin \varphi) \cos \left(\sin ^{-1}(\sin \varphi /(2-\sin \varphi))\right)$. 


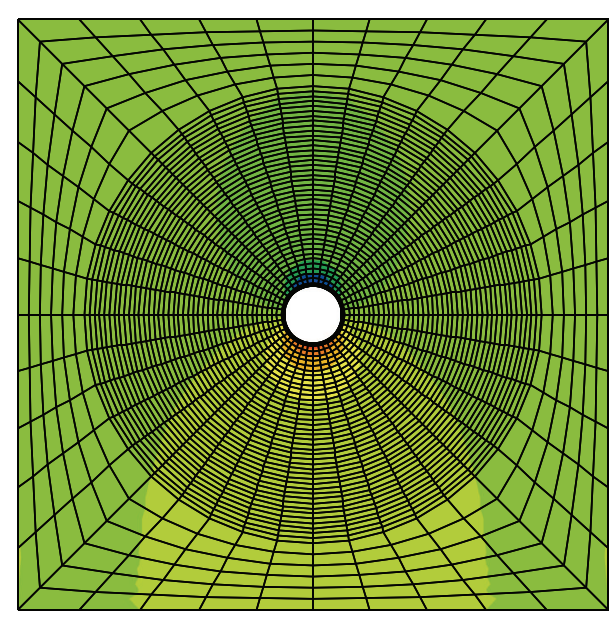

(a) $\sigma_{2}=15 \mathrm{MPa}$

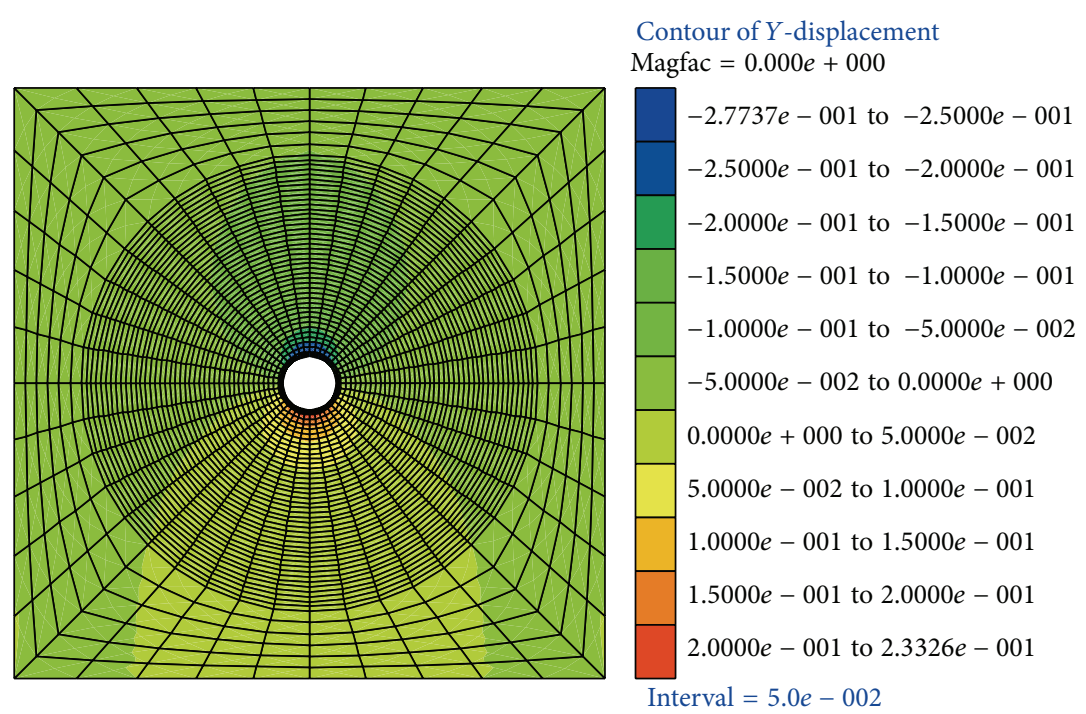

Contour of $Y$-displacement Magfac $=0.000 e+000$

(b) $\sigma_{2}=10 \mathrm{MPa}$
Contour of $Y$-displacement

Magfac $=0.000 e+000$

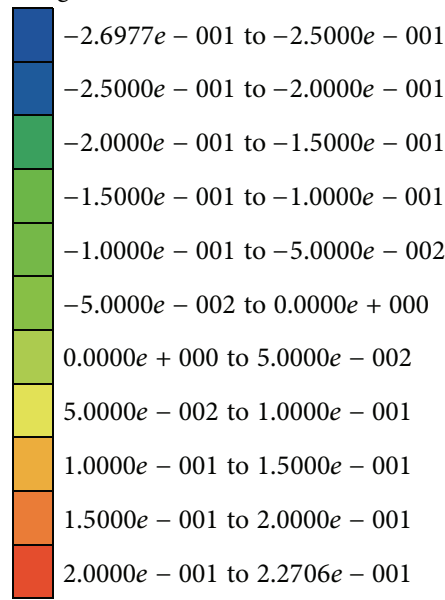

Interval $=5.0 e-002$

FIgURE 4: Vertical displacement (m).

$\varphi^{\prime}, c^{\prime}$ are equivalent internal friction angle and equivalent cohesion, respectively, in equivalent Mohr-Coulomb failure criterion. $\varphi$ and $c$ are internal friction angle and cohesion, respectively, in Mohr-Coulomb failure criterion.

3.2. Description of Numerical Model. Properties of geomaterials are shown in Table 2. The numerical simulation employs the equivalent Mohr-Coulomb failure criterion (polyaxial failure criterion). According to the established relationship as shown in (8) and (9) between Mohr-Coulomb failure criterion and polyaxial failure criterion, polyaxial failure criterion can be equivalently substituted in the numerical simulation by inputting equivalent cohesion and equivalent internal friction angle into Mohr-Coulomb failure criterion. This numerical simulation includes six cases: case I: $\sigma_{2}=$ $5 \mathrm{MPa}$; case II: $\sigma_{2}=10 \mathrm{MPa}$; case III: $\sigma_{2}=15 \mathrm{MPa}$; case IV: $\sigma_{2}=20 \mathrm{MPa}$; case V: $\sigma_{2}=25 \mathrm{MPa}$; case VI: $\sigma_{2}=50 \mathrm{MPa}$.
The model mainly adopts stress boundary, except the base of the model and boundaries perpendicular to $Z$-axis, both of which employ the displacement boundary condition. Based on actual requirements, stress boundary is specified on the rest of boundaries as shown in Figure 7. In order to simulate the effect of intermediate principal stress well and eliminate the influence of other factors affecting numerical results, this research adopts $3 \mathrm{D}$ (three-dimensional) model with full excavation method. During the simulating process, blasting cycle is $1 \mathrm{~m}$ and support system is not installed.

\subsection{Numerical Results}

3.3.1. Analysis on Displacement. In the six cases above, crown displacement curve, horizontal convergence curve, and invert uplift curve are shown in Figure 8. 
TABLE 2: Equivalent parameters under equivalent Mohr-Coulomb failure criterion.

\begin{tabular}{|c|c|c|c|c|c|c|}
\hline$\sigma_{2}$ & $5 \mathrm{Mpa}$ & $10 \mathrm{Mpa}$ & $15 \mathrm{Mpa}$ & $20 \mathrm{Mpa}$ & $25 \mathrm{Mpa}$ & $50 \mathrm{Mpa}$ \\
\hline$c_{\mathrm{eq}}$ & $2.436 \mathrm{MPa}$ & $4.204 \mathrm{MPa}$ & $5.972 \mathrm{MPa}$ & $7.739 \mathrm{MPa}$ & $9.507 \mathrm{MPa}$ & $18.346 \mathrm{MPa}$ \\
\hline$\varphi_{\mathrm{eq}}$ & $19.47^{\circ}$ & $19.47^{\circ}$ & $19.47^{\circ}$ & $19.47^{\circ}$ & $19.47^{\circ}$ & $19.47^{\circ}$ \\
\hline
\end{tabular}

Note: $c, \varphi$ are $0.2 \mathrm{MPa}$ and $30^{\circ}$, respectively, under Mohr-Coulomb failure criterion.

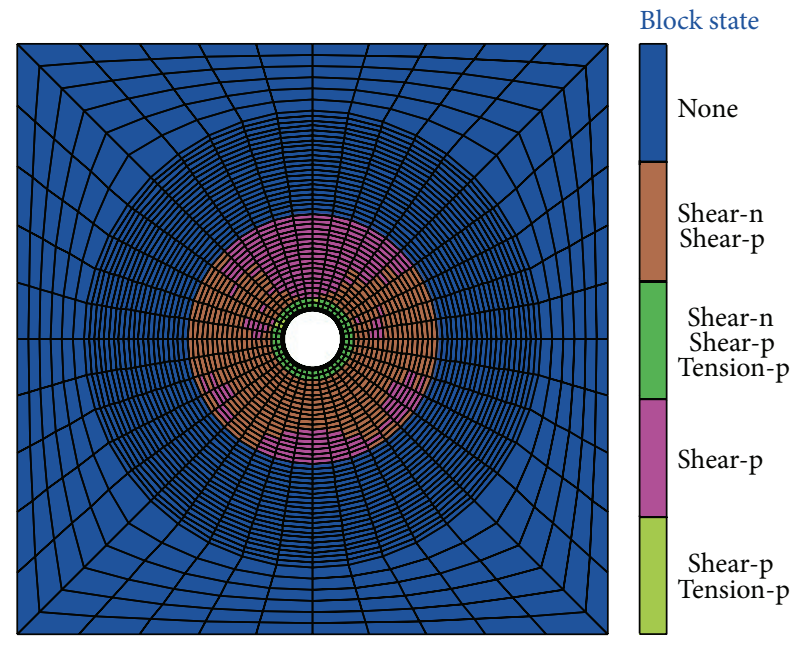

(a) $\sigma_{2}=15 \mathrm{MPa}$

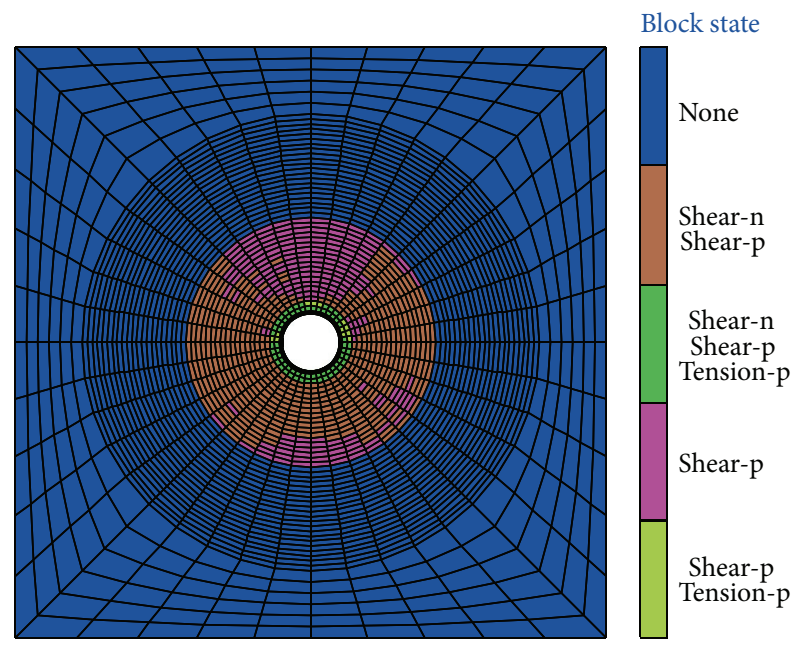

(b) $\sigma_{2}=10 \mathrm{MPa}$

Figure 5: Plastic zone (m).

Figure 8 shows that deformation value tends to decrease with increment of intermediate principal stress and represents a nonlinear characteristic. When $\sigma_{2} \geqslant 20 \mathrm{MPa}$, deformation of the rock mass tends to be constant; when $\sigma_{2} \geqslant 20 \mathrm{MPa}$, rock strength enhancement brought by $\sigma_{2}$ is not significant. It is worth noting that since support structure system is not installed during the numerical simulation, minor principal stress $\sigma_{3}$ equals $0 \mathrm{MPa}$ on the tunnel surface; it is also worth noting that when the intermediate principal stress $\sigma_{2} \geqslant 20 \mathrm{MPa}$, displacement controller of the rock mass begins to become minor principal stress $\sigma_{3}$ instead of intermediate principal stress $\sigma_{2}$.

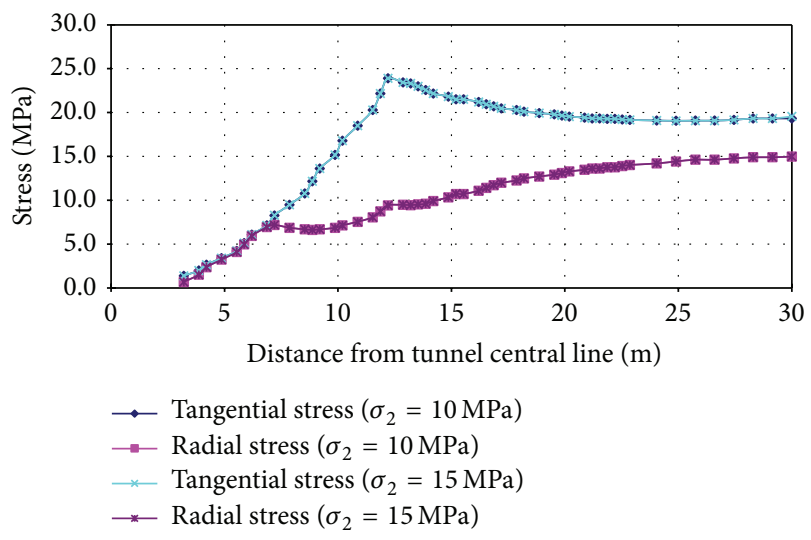

FIgURE 6: Stress distribution of rock mass.

3.3.2. Analysis on Plastic Zone. The plastic zone with different intermediate principal stress is shown in Figures 9 11. Curve of plastic zone radius shares the same characteristics as displacement curve. Figure 12 shows that effect of intermediate principal stress on the area of plastic zone decreases with the increment of intermediate principal stress.

3.3.3. Analysis of Stress Distribution. After excavation, rock masses around the excavation may fall into plastic state if stress of rock is greater than rock strength, resulting in plastic and shear slip or plastic flow of the rock mass. According to rock mechanics [12], when rock masses fall into plastic state, deformation increases without the change of stress. Based on the rock stress redistribution theory of unsupported tunnel, excavation produces a limited stress concentration at tangential direction. In other words, tangential stress $\sigma_{\theta}$ continues to increase within a certain distance; if the distance to the tunnel surface is greater than the distance, tangential stress $\sigma_{\theta}$ decreases. When $\sigma_{\theta}$ reaches the maximum value, the corresponding distance to the tunnel surface represents the maximum size of the plastic zone.

The results show that radial stress and tangential stress share the same distribution characteristics. With the increment of intermediate principal stress $\sigma_{2}$, the maximum tangential stress also tends to increase, shown in Figures 13 15. Specifically, the maximum tangential stresses are $22.3 \mathrm{MPa}$ $\left(\sigma_{2}=5 \mathrm{MPa}\right), 23.4 \mathrm{MPa}\left(\sigma_{2}=10 \mathrm{MPa}\right), 25.1 \mathrm{MPa}\left(\sigma_{2}=\right.$ $15 \mathrm{MPa}), 25.7 \mathrm{MPa}\left(\sigma_{2}=20 \mathrm{MPa}\right), 28.2 \mathrm{MPa}\left(\sigma_{2}=25 \mathrm{MPa}\right)$, and $28.2 \mathrm{MPa}\left(\sigma_{2}=30 \mathrm{MPa}\right)$, respectively. Besides, the results indicate that with the increment of intermediate principal stress $\sigma_{2}$ area of stress redistribution tends to be smaller gradually. 


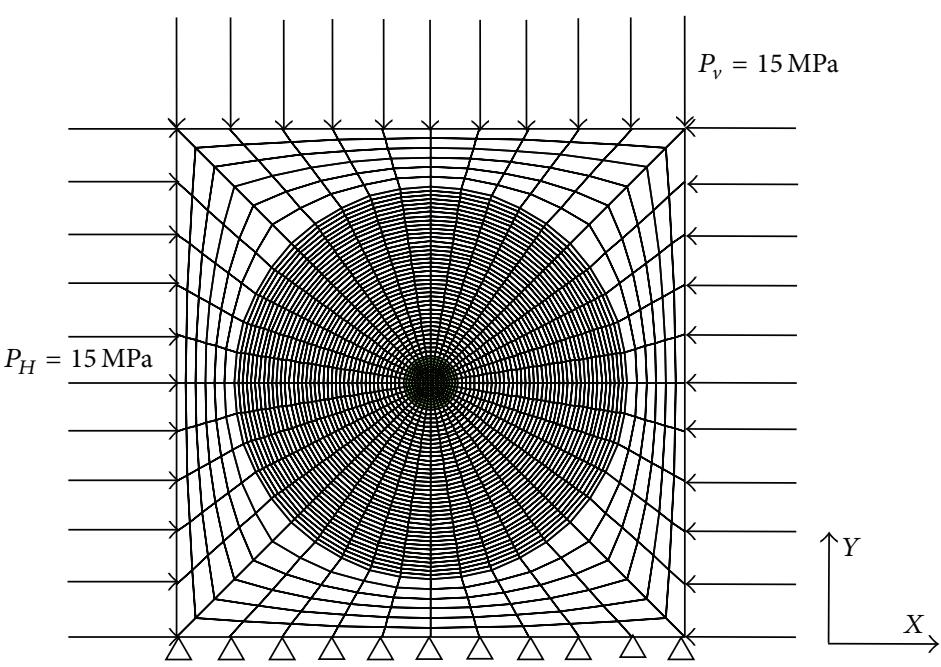

(a) Front view

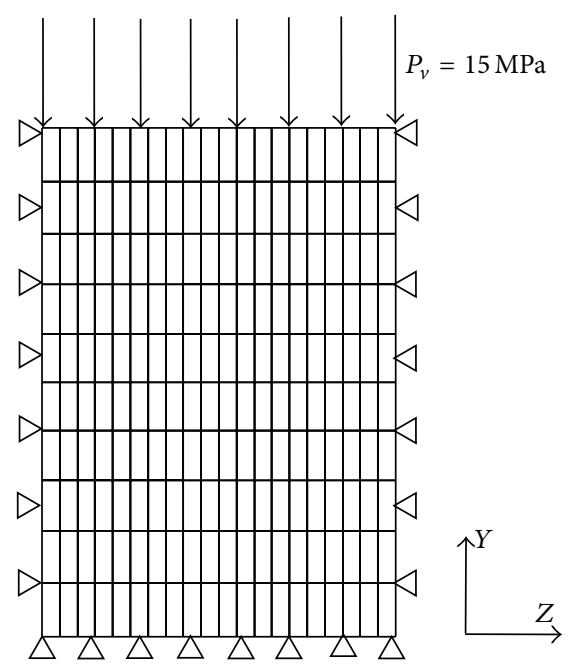

(b) Lateral view

Figure 7: Numerical simulation.

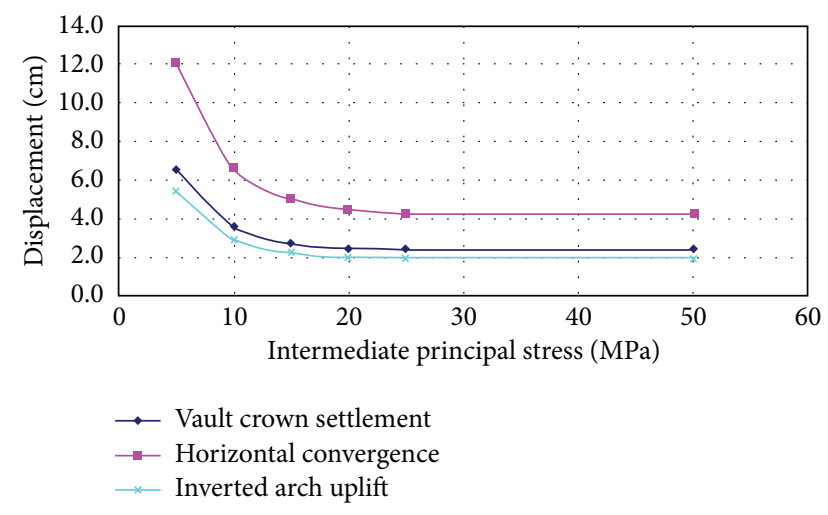

FIGURE 8: Displacement with increment of intermediate principal stress.

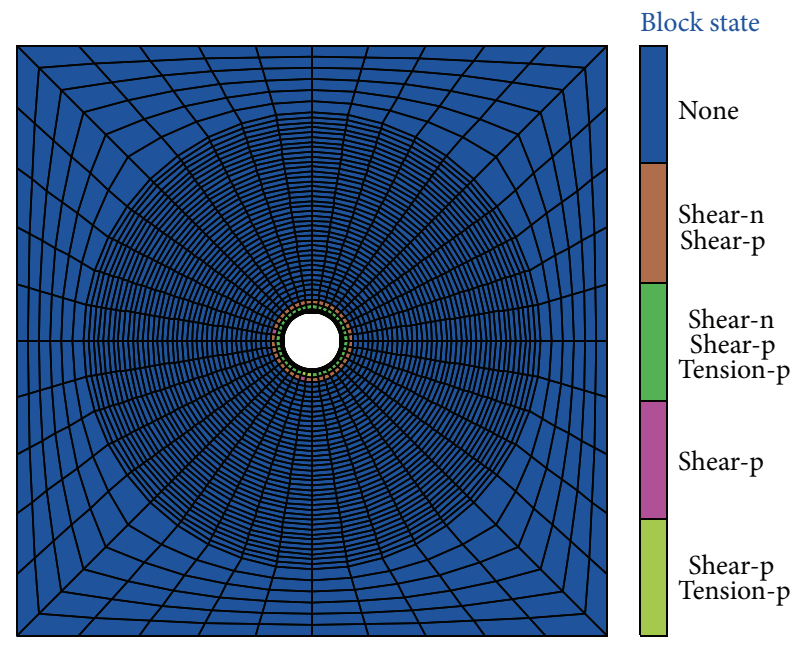

FIgURe 10: Plastic zone, $\sigma_{2}=15 \mathrm{MPa}$ (radius: $4.20 \mathrm{~m}$ ).

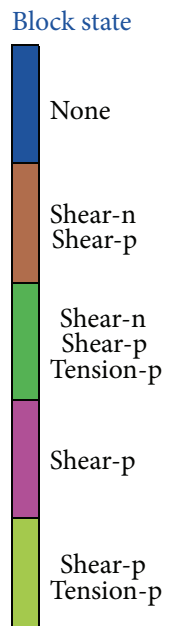

Figure 9: Plastic zone, $\sigma_{2}=5 \mathrm{MPa}$ (radius: $6.70 \mathrm{~m}$ ).

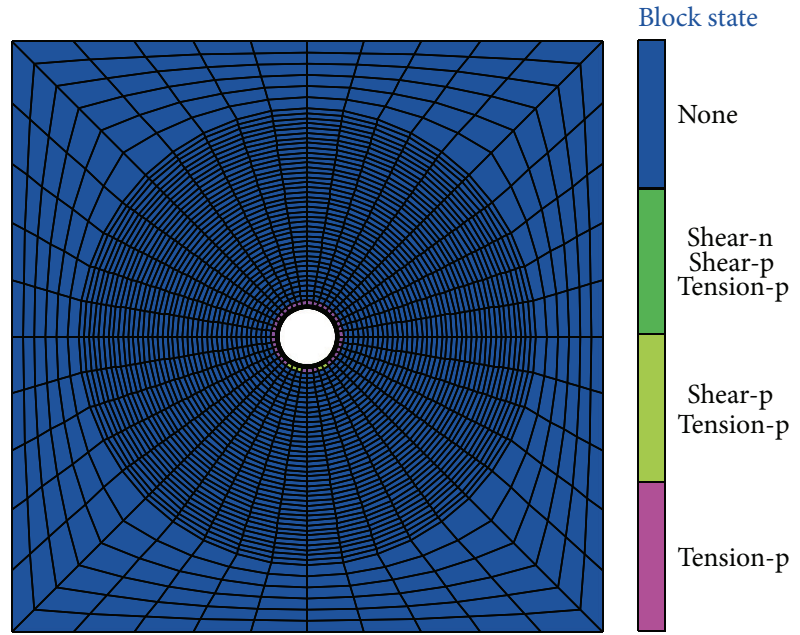

FIgURe 11: Plastic zone, $\sigma_{2}=25 \mathrm{MPa}$ (radius: $3.60 \mathrm{~m}$ ). 


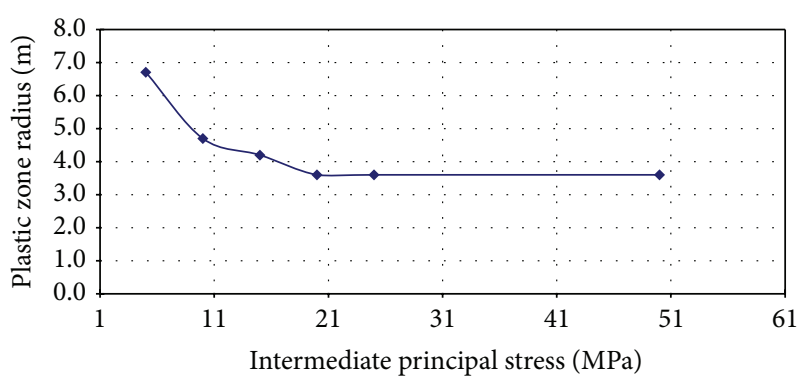

Figure 12: Plastic zone radius with increment of intermediate principal stress.

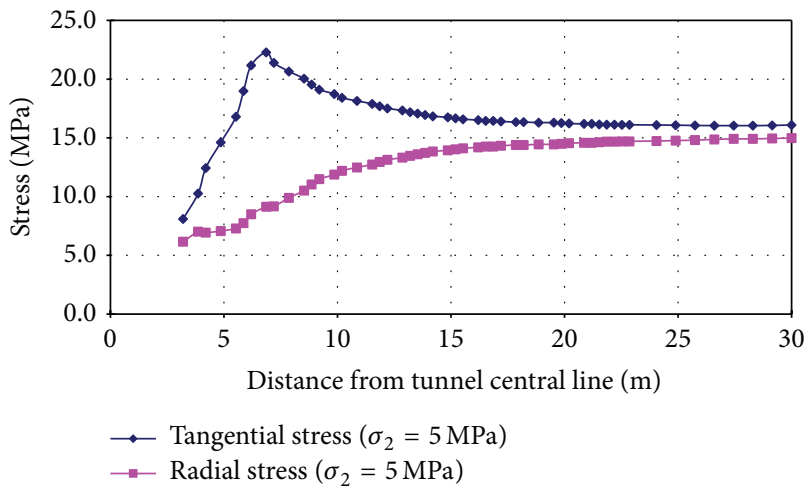

FIGURE 13: Stress distribution of rock mass $\left(\sigma_{2}=5 \mathrm{MPa}\right)$.

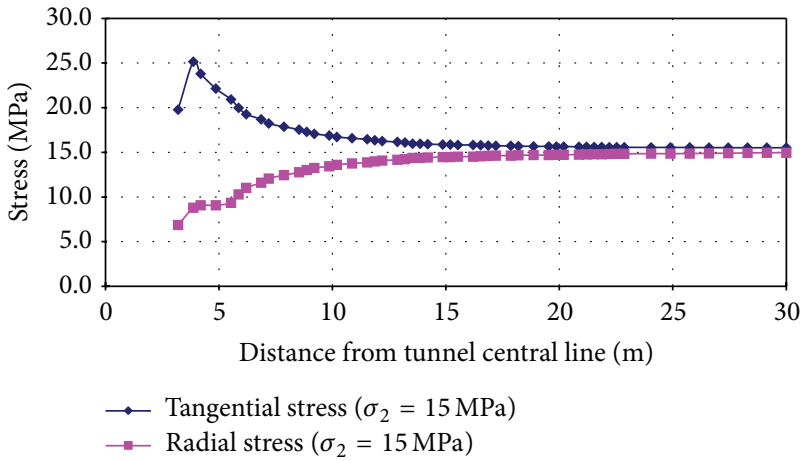

FIGURE 14: Stress distribution of rock mass $\left(\sigma_{2}=15 \mathrm{MPa}\right)$.

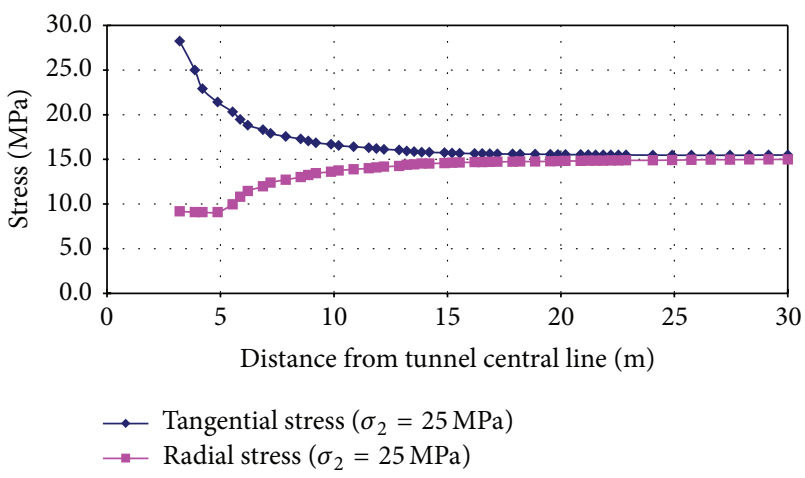

FIGURE 15: Stress distribution of rock mass $\left(\sigma_{2}=25 \mathrm{MPa}\right)$.

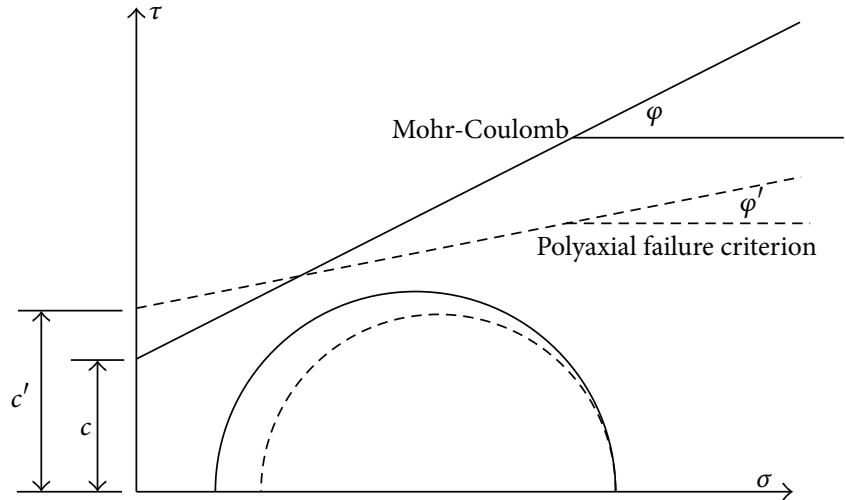

FIGURE 16: Mohr-Coulomb envelope and polyaxial envelope.

TABLE 3: Internal friction angle $\varphi$ and equivalent internal friction angle $\varphi^{\prime}$.

\begin{tabular}{lcccccc}
\hline$\varphi\left(^{\circ}\right)$ & 15 & 20 & 25 & 30 & 35 & 40 \\
\hline$\varphi^{\prime}\left(^{\circ}\right)$ & 8.55 & 11.90 & 15.54 & 19.47 & 23.71 & 28.27 \\
\hline
\end{tabular}

TABLE 4: Cohesion $c$ and equivalent cohesion $c^{\prime}$.

\begin{tabular}{lcccccc}
\hline$c(\mathrm{MPa})$ & 15 & 20 & 25 & 30 & 35 & 40 \\
\hline$c^{\prime}(\mathrm{MPa})$ & 2.44 & 4.20 & 5.97 & 7.74 & 9.51 & 11.27
\end{tabular}

TABLE 5: Results of numerical simulation.

\begin{tabular}{lcc}
\hline Failure criterion & Settlement at crown & Radius of plastic zone \\
\hline M-C & $26.97 \mathrm{~cm}$ & $12.64 \mathrm{~m}$ \\
Ploy & $70.63 \mathrm{~cm}$ & $24.16 \mathrm{~m}$ \\
\hline
\end{tabular}

\section{Discussions}

The relationship between cohesion $c$ and equivalent cohesion $c^{\prime}$ and the relationship between internal friction $\varphi$ and equivalent internal friction $\varphi^{\prime}$ are written as (8) and (9), respectively. According to (8) (9), equivalent cohesion and equivalent internal friction used in the numerical simulation are shown in Tables 3 and 4, respectively.

From (8) and (9), Mohr-Coulomb failure criterion envelope and polyaxial failure criterion envelope on $\tau-\sigma$ coordinate system are shown in Figure 16.

Figure 16 shows that, for polyaxial failure criterion, effect of intermediate principal stress on rock strength is explained that internal friction is reduced and meanwhile cohesion is increased. Equations (2) (3) indicate that the effect of $\sigma_{3}$ under Mohr-Coulomb failure criterion is smaller than that under polyaxial failure criterion, when intermediate principal stress $\sigma_{2}$ is $=0$. As a result, when intermediate principal stress $\sigma_{2}=0$ or rock strength enhancement brought by $\sigma_{2}$ can be ignored (such as tunnel portal), it is improper that numerical simulation is executed using polyaxial failure criterion. Table 5 shows settlement of the crown and radius of plastic zone when Mohr-Coulomb failure criterion and polyaxial failure criterion are applied, respectively, in the numerical simulation. 


\section{Conclusions}

(1) The results of numerical simulation under MohrCoulomb failure criterion show that the intermediate principal stress $\sigma_{2}$ does not exert a significant influence on stress redistribution and displacement at crown as well as the size of plastic zone in numerical simulation.

(2) Intermediate principal stress has a significant enhancement on rock strength. Specifically, greater $\sigma_{2}$ not only significantly reduces the displacement at the crown and excavation disturbance area as well as the size of plastic zone but also improves the bearing capacity of rock mass. Particularly for the squeezing condition, effect of $\sigma_{2}$ is significant. As a result, for squeezing geocondition where lateral pressure coefficient $K$ is greater than 0.5 Mohr-Coulomb is not applicable to analyze the mechanical behavior of rock mass.

(3) For polyaxial failure criterion, effect of intermediate principal stress on rock strength enhancement is explained that internal friction angle is reduced and meanwhile cohesion is increased.

(4) The effect of $\sigma_{3}$ under Mohr-Coulomb failure criterion is smaller than that under polyaxial failure criterion, when intermediate principal stress $\sigma_{2}$ is $=0$ or is small. As a result, when in tunnel portal $\left(\sigma_{2}\right.$ is much smaller than other principal stresses), using polyaxial failure criterion in numerical simulation is not proper.

\section{Conflict of Interests}

The authors declare that there is no conflict of interests regarding the publication of this paper.

\section{Acknowledgments}

The authors gratefully acknowledge the financial support to this study from NSFC (Natural Science Foundation of China) (U1434206, 51378321, and 51208437) and the Fundamental Research Funds for the Central Universities (2682015CX095).

\section{References}

[1] E. Hoek, P. K. Kaiser, and W. F. Bawden, Support of Underground Excavations in Hard Rock, Funding by Mining Research Directorate and Universities Research Incentive Fund, A.A. Balkema Publishers, 1993.

[2] S. Senent, R. Jimenez, and A. Reyes, "Numerical simulation of the influence of small-scale defects on the true-triaxial strength of rock samples," Computers and Geotechnics, vol. 53, pp. 142156, 2013.

[3] R. Wang and J. M. Kemeny, "A new empirical failure criterion under polyaxial compressive stresses," in Proceedings of the 35th U.S. Symposium on Rock Mechanics, J. J. K. Daemen and R. A. Schultz, Eds., pp. 453-459, Reno, Nev, USA, 1995.
[4] Z.-H. Li, W.-C. Zhu, X.-T. FenG, S.-J. Li, H. Zhou, and B.R. Chen, "Effect of lateral pressure coefficients on damage and failure process of horseshoe-shaped tunnel," Rock and Soil Mechanics, vol. 31, pp. 434-461, 2010 (Chinese).

[5] B. Singh, R. K. Goel, V. K. Mehrotra, S. K. Garg, and M. R. Allu, "Effect of intermediate principal stress on strength of anisotropic rock mass," Tunnelling and Underground Space Technology, vol. 13, no. 1, pp. 71-79, 1998.

[6] B. Singh and R. K. Goel, Tunnelling in Weak Rocks, vol. 5 of GeoEngineering, Elsevier Science, 2006.

[7] D. Scussel and S. Chandra, "New approach to the design of tunnels in squeezing ground," International Journal of Geomechanics, vol. 14, no. 1, pp. 110-117, 2014.

[8] N. Barton, R. Lien, and J. Lunde, "Engineering classification of rock masses for the design of tunnel support," Rock Mechanics Felsmechanik Mécanique des Roches, vol. 6, no. 4, pp. 189-236, 1974.

[9] D. Scussel and S. Chandra, "Polyaxial stress analysis of underground openings using FLAC," Journal of Rock Mechanics and Tunnel Technologies, vol. 18, no. 1, pp. 41-54, 2012.

[10] Itasca User's Guide for FLAC3D, Version 3.0, 2005.

[11] D. Scussel and S. Chandra, "A new approach to obtain tunnel support pressure for polyaxial state of stress," Tunnelling and Underground Space Technology, vol. 36, pp. 80-88, 2013.

[12] G. Baoshu, Tunnel Mechanics, Southwest Jiaotong University Press, 1993. 


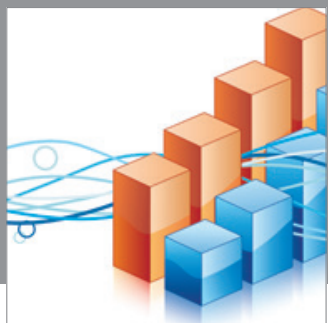

Advances in

Operations Research

mansans

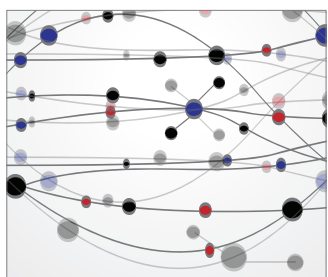

The Scientific World Journal
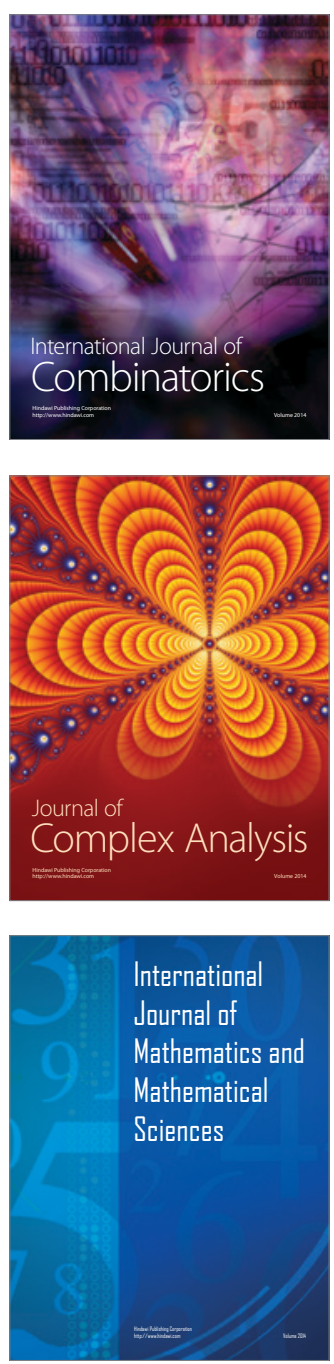
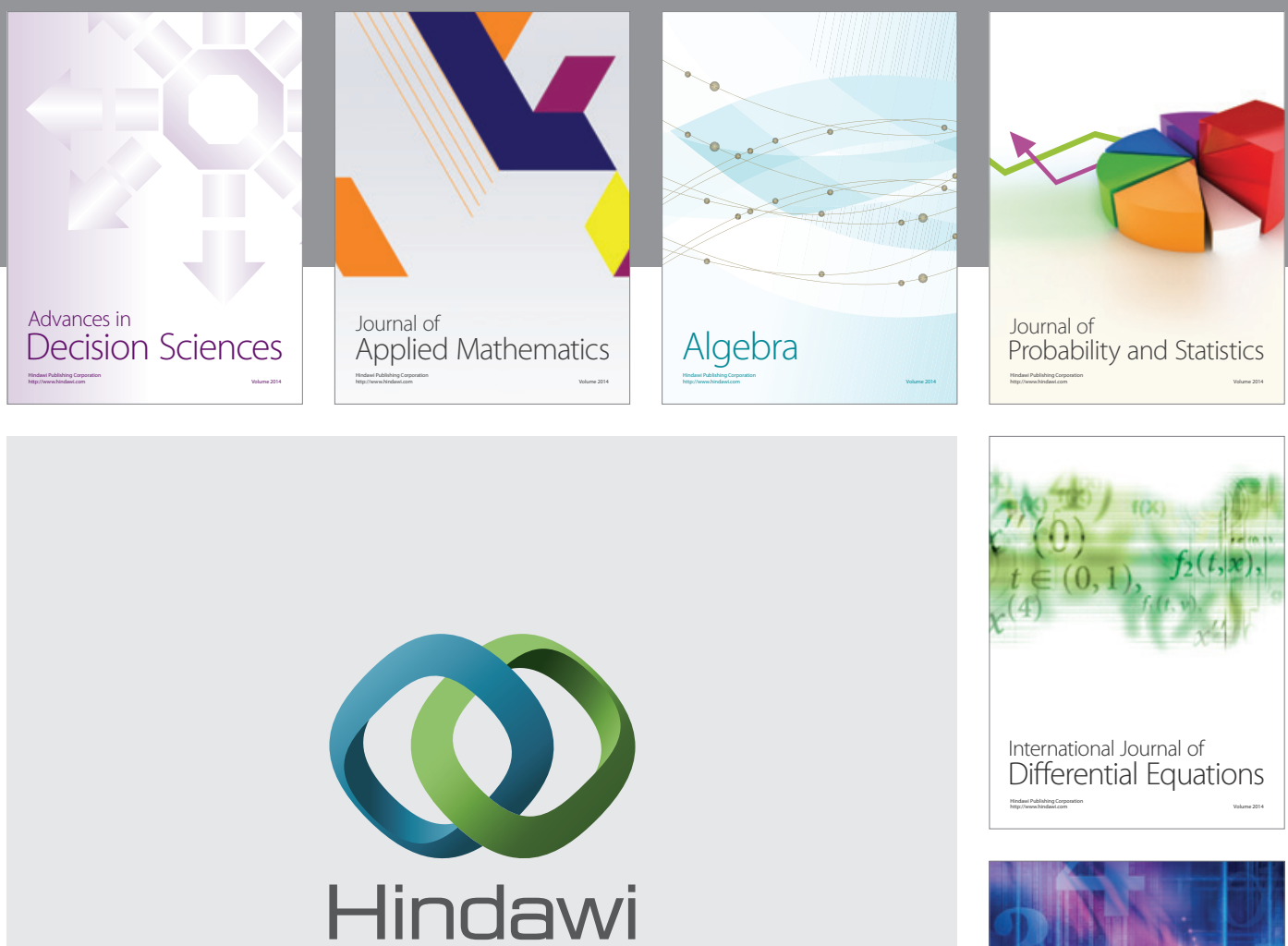

Submit your manuscripts at http://www.hindawi.com
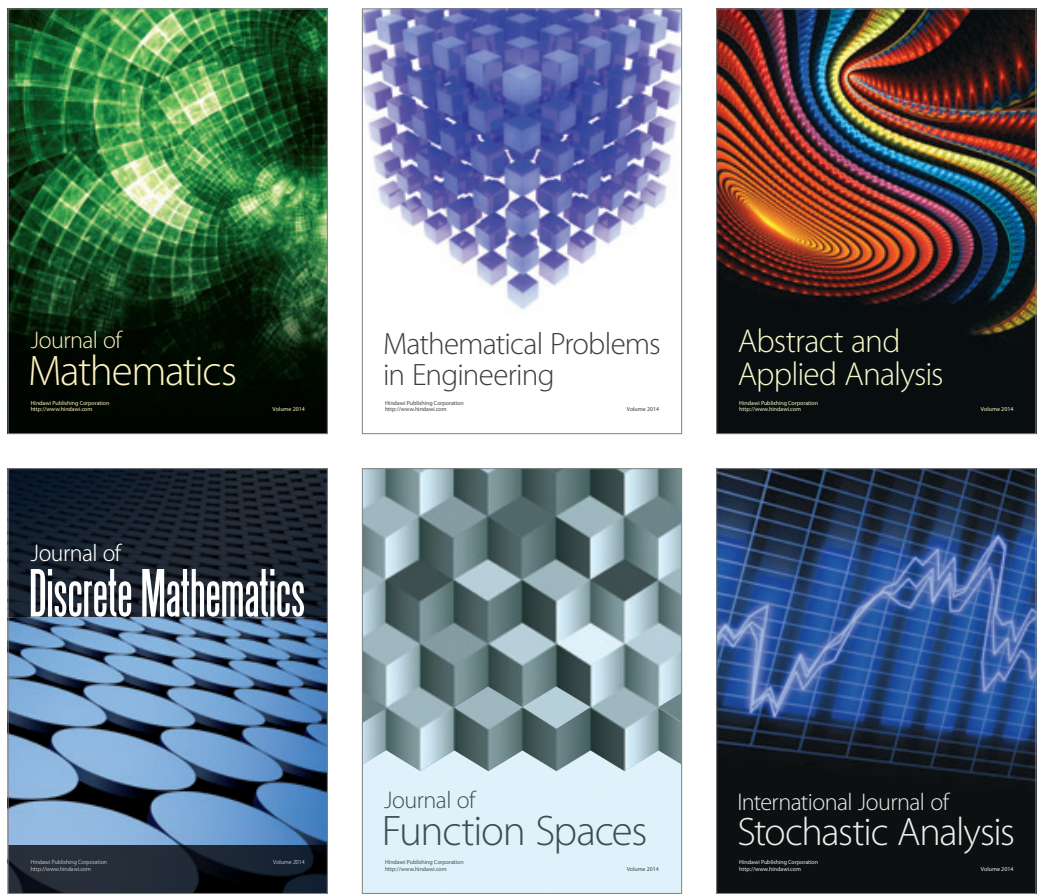

Journal of

Function Spaces

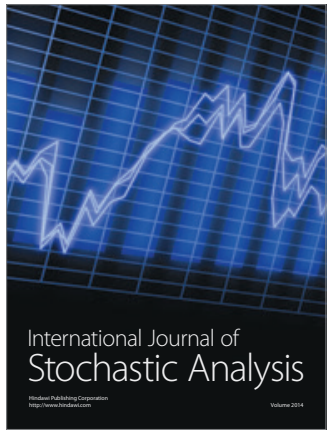

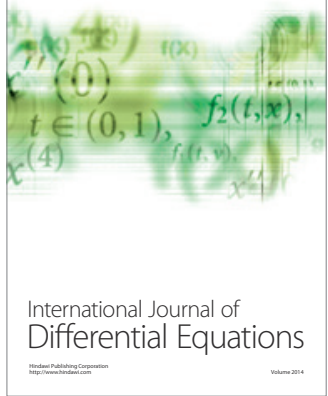
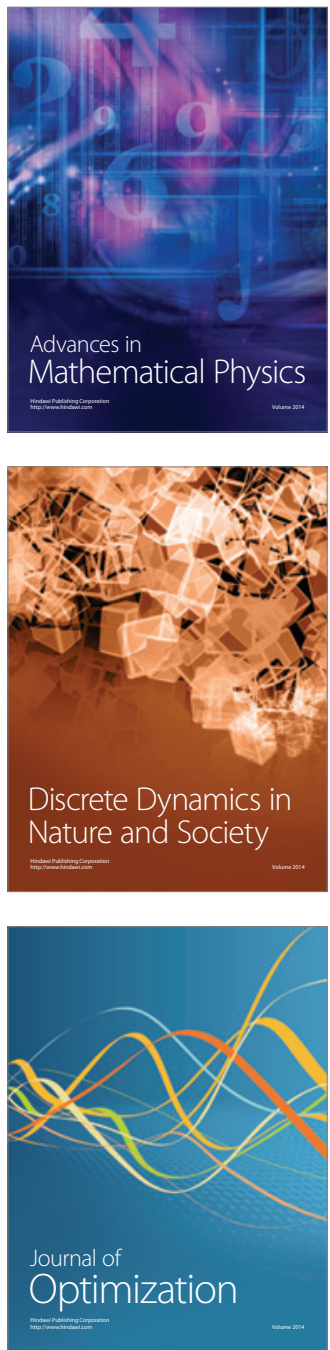